Discussion Paper No. 783

\title{
CAN THE CONSUMPTION-FREE NONEXPECTED UTILITY MODEL SOLVE THE RISK PREMIUM PUZZLE? \\ AN EMPIRICAL STUDY OF THE JAPANESE STOCK MARKET
}

Myong-Il Kang

June 2010

The Institute of Social and Economic Research

Osaka University

6-1 Mihogaoka, Ibaraki, Osaka 567-0047, Japan 
Can the Consumption-Free Nonexpected Utility Model Solve the Risk Premium Puzzle? An Empirical Study of the Japanese Stock Market

\author{
Myong-Il Kang ${ }^{* \dagger}$ \\ Korea University
}

June 17, 2010

\footnotetext{
* Correspondence: M Kang, Assistant professor, Department of Business Administration, Korea University, 1-700 Ogawa-cho, Kodaira, Tokyo 187-8560, JAPAN. Tel: +81-42-341-1331. Fax: +81-42-344-1300. E-mail: mkang@korea-u.ac.jp.

${ }^{\dagger}$ This paper is a part of the visiting research of the Institute of Social and Economic Research, Osaka University. My special thanks go to S. Ikeda for helpful comments, and I am also grateful to Y. Fukuta, K. Hirata, K. Kubota, H. Nakaota, K. Nishina, M. Ohnishi, F. Ohtake, K. Oya, Y. Tanigawa, and participants at the 2004 Annual Meeting of the Japanese Economic Association, Okayama University, for beneficial discussions. I acknowledge a financial support by the Grant-in-Aid for JSPS Fellows (188689), the Ministry of Education, Culture, Sports, Science and Technology.
} 


\begin{abstract}
This paper investigates whether the consumption-free two-beta intertemporal capital asset-pricing model developed by Campbell and Vuolteenaho (2004) is able to solve the risk premium puzzle in the Japanese stock market over the period 1984-2002. Using the cash flow and discount rate betas as risk factors, the model is able to explain about half of the market returns by selection of suitable vector autoregression variables. On this basis, the model proposed solves the risk premium puzzle in Japan, thereby suggesting that Japanese investors are less risk averse than US investors. However, a model including only the cash flow beta better explains returns than a model with both betas. The analysis also tests and rejects the simple capital asset-pricing model in Japan.
\end{abstract}

Key words: Risk premium puzzle, Nonexpected utility, CAPM

JEL classification: G12 


\section{Introduction}

Since Mehra and Prescott (1985) first identified the risk premium puzzle, many researchers have investigated whether the Lucas (1978) and Breeden (1979) form of the consumption-based capital asset-pricing model (C-CAPM) is compatible with the Japanese stock market. Using Hansen's (1982) Generalized Method of Moments, Hamori (1992) showed that the power utility type C-CAPM exhibits good performance with low-risk parameters while Hamori (1994) verified that the Epstein and Zin (1989, 1991) nonexpected utility type C-CAPM explains returns better in the Japanese equity market. Conversely, Tanigawa (1994) and Hori (1996) retested these models using the Hansen and Jagannathan (1991) bound test and rejected both. Nakano and Saito (1998) also applied these models to three Japanese markets—stock, land, and bonds—and verified their poor performance. Importantly, all of these models explicitly contain a consumption variable in the pricing kernel, and thus could not avoid the harmful effects arising from the use of aggregate consumption data: often incriminated as the cause of the risk premium puzzle because of aggregation bias, the infrequent reporting of consumption, sampling error, and smoothing associated with seasonal adjustment.

To avoid these problems with the use of aggregate consumption data, Campbell and Vuolteenaho (2004) develop a consumption-free intertemporal capital asset-pricing model (hereafter, CV model) assuming Epstein-Zin nonexpected utility. They solve the discrete-time version of Merton's ICAPM by using a dividend ratio model (Campbell, 1988a) and return decomposition (Campbell, 1991). The induced model includes two risk factors, the cash flow beta and the discount rate beta, both of which are endogenously determined. The former measures the correlation between asset returns and unexpected fluctuations in future cash flows (cash flow news) while the latter measures future discount rates (discount rate news). Campbell and Vuolteenaho (2004) decompose unexpected market returns into two components by assuming that the market variables follow a first-order vector autoregression (VAR) process, and find that the model empirically solves the risk premium puzzle with a low-risk aversion parameter in the US stock market.

The focus of this paper is whether the CV model also solves the risk premium puzzle in Japan. For this purpose, we empirically investigate the validity of the CV model for Japanese stock returns, and 
compare it with a factor model and the simple capital asset-pricing model (CAPM). We select five variables as VAR state variables suitable for the Japanese data and estimate two betas as risk factors. The main contribution is that we demonstrate that the CV model is valid in Japan with high adjusted R-squared values (52.2\% and 24.6\%), and solve the risk premium puzzle with low values of the relative risk aversion (RRA) parameter (2.80 and 2.05). Given that the estimated RRA is lower than in the US, we conjecture that Japanese investors are less risk averse than investors in the US. We also find that a single-factor model only including a cash flow beta can successfully explain Japanese stock returns and reject the CAPM.

The remainder of the paper is organized as follows. Section 2 introduces the CV model. Section 3 discusses the variables used as state variables in the VAR, generates data on the two news variables, and estimates their betas. We also empirically analyze the Japanese stock market by comparing the CV model with the factor model and the CAPM, and estimate the RRA coefficient. Section 4 provides the conclusion.

\section{Model}

Consider a stock that pays dividends $D_{t+1}$ at the end of the period. Letting $P_{t}$ denote the price of the stock at time $t$, returns $R_{t}$ are:

$$
R_{t+1}=\frac{P_{t+1}+D_{t+1}}{P_{t}}
$$

Taking logarithms of both sides of equation (1) and using a Taylor expansion, the log of $R_{t}, r_{t}$, can be expressed approximately as linear in the logs of $P_{t}$ and $D_{t+1}$ :

$$
r_{t+1} \approx k+\rho p_{t+1}+(1-\rho) d_{t+1}-p_{t}
$$

where $\rho \equiv 1 /\left(1+\exp \overline{\left(d_{t}-p_{t}\right)}\right) ; k \equiv-\ln (\rho)-(1-\rho) \ln (1 / \rho-1) ;$ and $\quad p_{t}$ and $d_{t+1}$ denote the logarithms of $P_{t}$ and $D_{t+1}$, respectively.

We solve equation (2) forward iteratively. By taking expectations and subtracting $d_{t}$ from both sides, we obtain the familiar Campbell and Shiller (1988a) formula:

$$
p_{t}-d_{t}=\frac{k}{1-\rho}+E_{t} \sum_{j=0}^{\infty} \rho^{j}\left[\Delta d_{t+1+j}-r_{t+1+j}\right]
$$


where $\Delta d_{t+1}\left(=d_{t+1}-d_{t}\right)$ denotes the log of dividend growth. This formula explains that the log of the price dividend ratio at time $t$ depends on expectations at time $t$ of the discounted sum of future dividend growth minus the discount rate.

We follow Campbell (1991) in decomposing unexpected returns into two of its component parts by using (3). Substituting equation (3) for $p_{t}$ and $p_{t+1}$ in (2) and rearranging obtains:

$$
\begin{aligned}
r_{t+1}-E_{t} r_{t+1} & =\left(E_{t+1}-E_{t}\right) \sum_{j=0}^{\infty} \rho^{j} \Delta d_{t+1+j}-\left(E_{t+1}-E_{t}\right) \sum_{j=1}^{\infty} \rho^{j} r_{t+1+j} \\
& =N_{C F, t+1}-N_{D R, t+1},
\end{aligned}
$$

where $\quad N_{C F, t+1}\left(=\left(E_{t+1}-E_{t}\right) \sum_{j=0}^{\infty} \rho^{j} \Delta d_{t+1+j}\right)$ denotes news about future cash flows and $N_{D R, t+1}\left(=\left(E_{t+1}-E_{t}\right) \sum_{j=1}^{\infty} \rho^{j} r_{t+1+j}\right)$ denotes news about future discount rates. ${ }^{1}$ Equation (4) implies that unexpected returns are composed of two parts: changes during the period from $t$ to $t+1$ in expectations of future cash flows $\left\{\Delta d_{t+1+j}\right\}_{j=0}^{\infty}$ and discount rates $\left\{r_{t+1+j}\right\}_{j=1}^{\infty}$. Let $r_{M, t}^{e}$ represent the excess return in period $t$ over the risk-free rate on the market portfolio. We define the betas as follows:

$$
\beta_{i, C F} \equiv \frac{\operatorname{Cov}\left(r_{i, t}, N_{C F, t}\right)}{\operatorname{Var}\left(r_{M, t}^{e}-E_{t-1} r_{M, t}^{e}\right)} \text { and } \beta_{i, D R} \equiv \frac{\operatorname{Cov}\left(r_{i, t},-N_{D R, t}\right)}{\operatorname{Var}\left(r_{M, t}^{e}-E_{t-1} r_{M, t}^{e}\right)} \text {. }
$$

Because discount rate news has a negative sign, the sum of the two betas equals the market beta:

$$
\beta_{i, M}=\beta_{i, C F}+\beta_{i, D R}
$$

Campbell and Vuolteenaho (2004) refer to $\beta_{i, C F}$ as the cash flow beta and $\beta_{i, D R}$ as the discount rate beta. ${ }^{2}$ Equation (6) indicates that we can decompose the market beta into the cash flow and discount rate betas.

We close the model by specifying the utility-maximizing behavior of consumers. Consider an

\footnotetext{
1 'News' is used to describe the revision of expectations during the two periods.

${ }^{2}$ Campbell and Vuolteenaho (2004) also refer to the cash flow beta as the 'bad beta' and the discount rate beta as the 'good beta'.
} 
infinitely lived representative consumer. He or she chooses the stochastic process of consumption $C_{t}$. Assume that the nonexpected utility function $U$ proposed by Epstein and Zin $(1989,1991)$ gives consumer preferences,

$$
U\left(C_{t}, E_{t}\left(U_{t+1}\right)\right)=\left[(1-\delta) C_{t}^{\frac{1-\gamma}{\theta}}+\delta\left(E_{t}\left(U_{t+1}^{1-\gamma}\right)\right)^{\frac{1}{\theta}}\right]^{\frac{\theta}{1-\gamma}}
$$

where $\theta$ satisfies $\theta \equiv(1-\gamma) /\left(1-\psi^{-1}\right), \quad \gamma$ represents the relative risk aversion (RRA) coefficient, $\psi$ the elasticity of intertemporal substitution (EIS), and $\delta$ the time discount factor. Letting $W_{t}$ denote wealth holding at time $t$, the budget constraint is given by $W_{t+1}=\left(1+R_{p, t+1}\right)\left(W_{t}-C_{t}\right)$. The representative consumer maximizes (7) subject to the budget constraint. The first-order condition is given by the Euler equation,

$$
1=E_{t}\left\{\left[\delta\left(\frac{C_{t+1}}{C_{t}}\right)^{-\frac{1}{\psi}}\right]^{\theta}\left[\frac{1}{\left(1+R_{p, t+1}\right)}\right]^{(1-\theta)}\left(1+R_{i, t+1}\right)\right\} .
$$

In equation (8), the pricing kernel—or intertemporal marginal rate of substitution (IMRS)—is given by $\left[\delta\left(\frac{C_{t+1}}{C_{t}}\right)^{-\frac{1}{\psi}}\right]^{\theta}\left[\frac{1}{\left(1+R_{p, t+1}\right)}\right]^{(1-\theta)}$, and is shown to depend on two factors, consumption growth and market returns. The resulting two-factor structure enables us to examine the asset pricing implications of both news items $\left(N_{C F}\right.$ and $N_{D R}$ ). Note that in the case of $\gamma=1$, the pricing kernel depends solely on market returns, i.e., the model reduces to CAPM, whereas when $\gamma=1 / \psi$, the pricing kernel depends solely on consumption growth, so that the C-CAPM holds. ${ }^{3}$

By assuming that consumption growth and asset returns follow a joint lognormal distribution, the logarithmic Euler equation is obtained from (8) as follows:

$$
E_{t}\left(r_{i, t+1}\right)-r_{f, t+1}+\frac{\sigma_{i, t}^{2}}{2}=\gamma \operatorname{Cov}_{t}\left(r_{i, t+1}, r_{p, t+1}-E_{t} r_{p, t+1}\right)+(1-\gamma) \operatorname{Cov}_{t}\left(r_{i, t+1},-N_{p, D R, t+1}\right) .
$$

Substituting (4) into (9) yields:

\footnotetext{
${ }^{3}$ With Epstein-Zin preferences, we can generally express the pricing kernel as the weighted product of consumption growth and market returns.
} 


$$
E_{t}\left(r_{i, t+1}\right)-r_{f, t+1}+\frac{\sigma_{i, t}^{2}}{2}=\gamma \operatorname{Cov}_{t}\left(r_{i, t+1}, N_{p, C F, t+1}\right)+\operatorname{Cov}_{t}\left(r_{i, t+1},-N_{p, D R, t+1}\right)
$$

which in turn can be rewritten using (6) as:

$$
E_{t}\left(r_{i, t+1}\right)-r_{f, t+1}+\frac{\sigma_{i, t}^{2}}{2}=\gamma \sigma_{p, t}^{2} \beta_{i, C F_{p}, t}+\sigma_{p, t}^{2} \beta_{i, D R_{p}, t} .
$$

Equation (11) indicates that two risk factors, the cash flow beta and the discount rate beta, determine the equity risk premium $i$. The risk price of the cash flow beta is $\gamma \sigma_{p, t}^{2}$ and the risk price for the discount rate beta is $\sigma_{p, t}^{2}$. The risk price of the cash flow beta is thus larger than the discount rate beta when the RRA coefficient $\gamma$ is greater than one.

\section{Empirical analysis}

In this section, we use Japanese stock market data to examine: (i) whether the CV model is valid in the Japanese stock market compared with the factor model and the CAPM, and (ii) how large the RRA is in Japan. We conduct the empirical tasks as follows. First, we generate data on the cash flow and discount rate news by estimating a VAR model. We also show that the VAR variables used in this study are more suitable for explaining Japanese economic data than those used by Campbell and Vuolteenaho (2004) in the US. Second, using the news data, we estimate the cash flow and discount rate betas for various portfolios. Third, we regress portfolio returns on these betas to test the empirical validity of the models and to estimate the value of the RRA coefficient.

\subsection{Data description and news and beta estimation}

To construct data on cash flow and discount rate news, we estimate a VAR model as follows:

$$
z_{t+1}=a+\Gamma z_{t}+\varepsilon_{t+1}
$$

where $z_{t}$ denotes an $m \times 1$ state vector, the first element of which is market portfolio returns with the other elements being specified later, $a$ is an $m \times 1$ constant vector, $\Gamma$ is an $m \times m$ VAR coefficient 
matrix, and $\varepsilon_{t+1}$ is the $m \times 1$ error term or shock vector.

Upon estimation of the VAR process, the news data $N_{C F, t+1}=\left(e 1^{\prime}+e 1^{\prime} \lambda\right) \varepsilon_{t+1}$ and $N_{D R, t+1}=e 1^{\prime} \lambda \varepsilon_{t+1}$ are constructed as affine transformations of the shock vector $\varepsilon_{t+1}$ :

$$
N_{C F, t+1}=\left(e 1^{\prime}+e 1^{\prime} \lambda\right) \varepsilon_{t+1} \text { and } N_{D R, t+1}=e 1^{\prime} \lambda \varepsilon_{t+1}
$$

where $\lambda \equiv \rho \Gamma(I-\rho \Gamma)^{-1}$ maps VAR shocks to news, $I$ denotes the $m \times m$ identity matrix, and $e 1$ is an $m \times 1$ vector with one in the first element and zero otherwise.

For the VAR variables in $z$, we first try four variables; the excess returns on the market index (ER), the term yield spread (YS), the price-book value ratio (PBR), and the value yield spread of small stocks (VS). We construct ER by taking the difference in stock returns and the risk-free rate. For stock returns, we use the Total Index of the DAIWA Stock Index 2 (DSI-2, hereafter) from the website of the Daiwa Institute of Research Ltd. For the risk-free rate, we use the monthly GENSAKI Rates (the rate in the repurchase agreement market) from the Financial and Economic Statistics Monthly published by the Research and Statistics Department of the Bank of Japan. ${ }^{4}$ YS is the difference between short- and long-term yields on the Nikkei Bond Indices at the end of the month. PBR is the average value of the price-book value ratios computed from all listed companies on the First Section of the Tokyo Stock Exchange. This data are from the Monthly Statistics Report published by the Tokyo Stock Exchange. The ratio is log transformed. VS is the difference in small index returns for value and growth stocks from the DSI-2. The data series span the period 1984:1-2002:12. Table 1 provides descriptive statistics for the state variables. Table 3 reports the results of the VAR estimation using the four variables. Although TY and YS

\footnotetext{
${ }^{4}$ The reference base for the DSI indices is the end of December 1983. There are four major DSI indices: (1) a Total Index that includes all securities listed on six markets (Tokyo, Osaka, and Nagoya Stock Exchanges, JASDAQ, TSE Mothers, and Hercules); (2) Style Indices, including large, small, value, and growth indices; (3) Sector Indices that correspond to various industrial sectors; and (4) Other Indices, which include stock indices for large nonfinancials and financials, and a nonfinancials total index. All of these indices are derived by weighting the total returns of composite stocks by their market. All of these indices have two types, DSI-1 and DSI-2: the former is based on floating shares and latter on all listed shares. For more details, see the Web site of Daiwa Capital Market Indices at http://www.dir.co.jp/InfoManage/datarsc.html.
} 
have large values of adjusted R-squared, the system overall has only a few significant coefficients. More importantly, ER has a negative adjusted R-squared and no significant coefficients. The poor performance of the VAR estimation clearly indicates that these four VAR variables are unable to capture the expectations among market participants and may be inappropriate for the purposes of our analysis.

To improve the performance of the VAR, we add the following two variables instead of VS: the growth rate of business failure (DEF) and bond yields (BY). DEF is the year-on-year growth rate of business failures obtained from Tokyo Syoko Research (TSR). BY are the three-month GENSAKI rates at month end for three-month contracts. These are from the monthly report published by the Japan Securities Dealers Association, then transformed into real terms and taking the three-month moving average. Table 4 shows the results of the VAR using these five variables. By adding new two variables, the number of significant coefficients and the value of the adjusted R-squared both improve. In particular, ER now has three significant coefficients and a positive adjusted R-squared of 1.69 .

We can compute the residuals using the estimated VAR coefficients and then decompose them into cash flow and discount rate news. Tables 5 and Table 6 provide descriptive statistics for the news calculated with the four-variable and five-variable VARs, respectively. Using the news data calculated above, we can compare the performance of the four-variable and five-variable VARs. Because cash flow news is the sum of discount rate news and the residuals of RP according to equation (13), the larger the VAR unpredictability, the greater the magnitude of the RP residuals and, as a consequence, the larger the cash flow news. Table 7 presents a comparison of the absolute sum, absolute average, and squared sum of both news calculated using four and five variables. As cash flow news for four variables is much larger than for five variables, we suspect that the four state variables have poorer prediction performance than the five state variables.

Using Equation (13), we decompose the variance of returns into three terms as follows:

$$
\operatorname{Var}\left(r_{t+1}-E_{t} r_{t+1}\right)=\operatorname{Var}\left(N_{C F, t+1}\right)+\operatorname{Var}\left(N_{D R, t+1}\right)-2 \operatorname{Cov}\left(N_{C F, t+1}, N_{D R, t+1}\right) .
$$

This expression indicates that we can decompose the variance of expected returns, i.e., variance of total news, into variance and covariance of both types of news. Table 8 provides a comparison of both VARs using the variance decomposition of news. In the case of four variables, the variance of cash flow news and covariance of news unnaturally consists of a greater portion of total news, while with five variables, total 
news decomposes well into both types of news. Accordingly, we use the news estimated by applying the VAR with five variables.

Next, we estimate the cash flow and discount rate betas. From definition (5) of the betas, these are estimated using the following equations:

$$
\hat{\beta}_{i, C F}=\frac{\hat{\operatorname{Cov}}\left(r_{i, t}, \hat{N}_{C F, t}\right)}{\hat{\operatorname{Var}}\left(\hat{N}_{C F, t}-\hat{N}_{D R, t}\right)} \text { and } \hat{\beta}_{i, D R}=\frac{\hat{\operatorname{Cov}}\left(r_{i, t},-\hat{N}_{D R, t}\right)}{\hat{\operatorname{Var}}\left(\hat{N}_{C F, t}-\hat{N}_{D R, t}\right)}
$$

We use 43 DSI-2 indices for the asset return data: 33 sector indices, 7 Daiwa sector indices, and 3 other indices. ${ }^{5}$ We estimate the betas for these assets using the news data obtained above. The results are included in Table 9. On average, the discount rate beta is larger than the cash flow beta, and the correlation coefficient between the betas takes a positive and low value of 0.187 . These features are similar to the US findings in Campbell and Vuolteenaho (2004).

\subsection{Tests for asset-pricing models}

Using these betas, we empirically compare three asset-pricing models: the factor model, the CV model, and the CAPM. Following Campbell and Vuolteenaho (2004), we assume three assumptions for equation (11). First, simple returns $\left.E_{t} \mid R_{i, t+1}-R_{f, t+1}\right\rfloor$ are used instead of log-returns on the left-hand side. Second, the moments are invariant throughout time, so that unconditional moments can replace conditional moments. Finally, the stock portfolio is a proxy for the market portfolio. ${ }^{6}$ Equation (11) can then be rewritten as follows:

$$
E\left[R_{i}-R_{f}\right]=\gamma \sigma_{M}^{2} \beta_{i, C F_{M}}+\sigma_{M}^{2} \beta_{i, D R_{M}} .
$$

Using the estimated betas as explanatory variables, we represent the regression equation for the CV model as:

$$
\overline{R_{i}^{e}}=g_{0}+g_{1} \hat{\beta}_{i, C F}+g_{2} \hat{\beta}_{i, D R}+e_{i},
$$

\footnotetext{
${ }^{5}$ See Footnote 4 for a short description of these indices.

${ }^{6}$ For explicit expression of the third assumption, we insert subscript $p$ into $M$.
} 
where $\overline{R_{i}^{e}} \equiv \overline{R_{i}}-\overline{R_{f}}$ is the simple mean of excess returns on asset $i$ and the slope parameters $g_{1}$ and $g_{2}$ are the prices of the risk factors. From equation (17), the ratio $g_{1} / g_{2}$ equals the RRA coefficient $\gamma$.

Following Campbell and Vuolteenaho (2004), each model is estimated in two different regression forms: the first with an unrestricted zero beta, and the second with a restriction that zero beta equals the GENSAKI rate. Each model includes White's heteroskedasticity consistent covariances. We also report the $95 \%$ critical value of a bootstrap using 2,500 simulated realizations.

We start by estimating the two-factor model with the cash flow and discount rate betas. We do this by regressing asset returns on both betas without imposing any restrictions on the risk prices. The results of these estimations are in the second and third columns of Table 10. The risk price of the cash flow beta is significantly positive whereas the risk price of the discount rate beta is insignificant with a large adjusted R-squared. Based on these results, we doubt that we could explain asset returns better using the single-factor model with a cash flow beta, so we regress returns on the cash flow and discount rate betas separately. Table 11 shows the results. In the single-factor specification, the cash flow beta is still significant and exhibits a value of adjusted R-squared larger than even the two-factor cases. In contrast, the discount rate beta remains insignificant. These findings suggest that only the cash flow beta significantly explains asset returns.

We next examine the CV model by running a regression with a restriction on the risk price of the discount rate beta, $g_{2}=\sigma_{M}^{2}$. ${ }^{7}$ The results are included in the fourth and fifth columns of Table 10. The estimated slope parameter $g_{1}$, which is the risk price of the cash flow beta, is significantly positive, implying that the CV model significantly predicts asset returns. The last row of Table 10 provides the RRA coefficient calculated by $\gamma=g_{1} / g_{2}$. This is 2.80 with an unrestricted zero beta and 2.05 with a restricted zero beta. These values are lower than in the US case and indicate that Japanese investors may be less risk averse than US investors. ${ }^{8}$ It is also noteworthy that we could solve the risk premium puzzle with this low-risk aversion parameter by applying the model to Japanese data. The results lead us to the conclusion that the $\mathrm{CV}$ model is useful for solving the risk premium puzzle in the Japanese stock market.

\footnotetext{
7 This restriction is from equation (11). In our data sets, $\sigma_{M}^{2}=0.00326$ computed from DSI- 2 .

${ }^{8}$ In the US case in Campbell and Vuolteenaho (2004), RRA equals 8.6 and 7.0, respectively.
} 
Lastly, we examine the CAPM with the restriction that both risk prices are equal, $g_{1}=g_{2}{ }^{9}$ The sixth and seventh columns of Table 10 report the results. Although the estimated coefficient is significantly positive, the value far exceeds average market portfolio returns; that is, the estimated risk price is significantly higher than that required by the CAPM specification. ${ }^{10}$ Accordingly, we conclude that a single-factor model with a market beta only marginally explains asset returns.

\section{Conclusion}

This paper investigates whether the consumption-free CV model better explains Japanese stock returns than the factor model and the traditional CAPM, and whether we can solve the risk premium puzzle, at least in Japan, using this model. In the analysis, we selected five VAR state variables (RP, YS, PBR, DEF, and BY) as being more suitable for Japanese data than the four variables used in the comparable US study. Using the estimated VAR coefficients, we decomposed unexpected returns into two components, and estimated the cash flow beta and the discount rate beta. We found the discount rate beta to be larger, on average, than the cash flow beta, and their low and positive correlation coefficient is consistent with the US case. We then tested three types of asset-pricing models: a two-factor model with two betas, the CV model, and the traditional CAPM.

The results of this analysis are as follows. Firstly, the single-factor model including only the cash flow beta better explained Japanese stock returns rather than a two-factor model including both betas. Second, the CV model is valid in the Japanese stock market, though with a somewhat lower adjusted R-squared than that found with the single-factor model. On this basis, we can solve the risk premium puzzle as the risk aversion parameter lies below three. Moreover, as the value of RRA is smaller than in comparable US studies, the implication is that Japanese investors are less risk averse than US investors. These results support previous findings by Hamori $(1992,1994)$ that the risk premium puzzle does not arise in Japan. Third, consistent with many previous studies, we reject the CAPM.

\footnotetext{
${ }^{9}$ This restriction is from CAPM theory and the definition of betas in Equation (5).

${ }^{10}$ The average of the excess market portfolio returns is 0.00062 in our data set.
} 


\section{References}

Breeden, D. T, 1979. An intertemporal asset-pricing model with stochastic consumption and investment opportunities. Journal of Financial Economics 7, 265-296.

Campbell, J. Y, 1991. A variance decomposition for stock returns. Economic Journal 101, 157-179.

Campbell, J. Y, 1993. Intertemporal asset pricing without consumption data. American Economic Review $83,157-179$.

Campbell, J. Y, 1996. Understanding risk and return. Journal of Political Economy 104, 298-345.

Campbell, J. Y., A. W. Lo, and A. C. Mackinlay, 1996. The Econometrics of Financial Markets (Princeton University Press).

Campbell, J. Y. and J. Mei, 1993. Where do betas come from? Asset price dynamics and the source of systematic risk. Review of Financial Studies 6, 567-592.

Campbell, J. Y. and R. J. Shiller, 1988a. The dividend-price ratio and expectations of future dividends and discount factors. Review of Financial Studies 1, 195-228.

Campbell, J. Y. and R. J. Shiller, 1988b. Stock price, earnings, and expected dividends. Journal of Finance 43, 661-676.

Campbell, J. Y, and L. M. Viceira, 1997. Strategic asset allocation (Oxford University Press).

Campbell, J. Y. and T. Vuolteenaho, 2004. Bad beta, good beta. American Economic Review 94, $1249-1275$.

Epstein, L. and S. Zin, 1989. Substitution, risk aversion, and the temporal behavior of consumption and asset returns: A theoretical framework. Econometrica 57, 937-996.

Epstein, L. and S. Zin, 1991. Substitution, risk aversion, and the temporal behavior of consumption and asset returns: A empirical investigation. Journal of Political Economy 99, 263-286.

Fama, E. F. and K. R. French, 1992. The cross-section of expected stock returns. Journal of Finance 47, $427-465$.

Fama, E. F. and K. R. French, 1993. Common risk factors in the returns on stand bonds. Journal of Financial Economics 33, 3-56.

Hamori, S, 1992. Test of C-CAPM for Japan: 1980-1988. Economics Letters, 38, 67-72. 
Hamori, S, 1994. The non-expected utility model and asset returns: Some evidence from Japan. Japanese Journal of Financial Economics, 1, 89-99.

Hansen, L. P. and R. Jagannathan, 1991. Implications of security market data for models of dynamic economies. Journal of Political Economy 99, 225-262.

Hori, K, 1996. C-CAPM in Japanese asset market: Reexamination (in Japanese). Osaka Economic Papers, $45,76-89$.

Lintner, J, 1965. The valuation of risky assets and the selection of risky investments in stock portfolios and capital budgets. Review of Economics and Statistics 47, 13-37.

Lucas, R. E. Jr., 1978. Asset prices in an exchange economy. Econometrica 46, 1429-1445.

Mehra, R. and E. C. Prescott. 1985, The equity premium: A puzzle. Journal of Monetary Economics, 15, $145-161$.

Merton, R. C, 1973. An intertemporal capital asset pricing model. Econometrica 41, 867-887.

Nakano, K. and M. Saito, 1998. Communication: Asset pricing in Japan. Journal of the Japanese and International Economies 12, 151-166.

Roll, R, 1977. A critique of the asset pricing theory's test; part I: On past and potential testability of the theory. Journal of Finance 49, 101-121.

Sharpe, W, 1964. Capital asset prices: A theory of market equilibrium under conditions of risk. Journal of Finance 19, 425-442.

Tanigawa, Y, 1994. Syouhi data wo motiita sisankakaku no jissyou bunseki (in Japanese). Okayama Economic Review, 25, 315-332. 
Table 1

Descriptive statistics of the four VAR state variables

\begin{tabular}{lcccc}
\hline & ER & YS & PBR & VS \\
\hline \hline Mean & 0.000619 & 0.000600 & 0.785574 & 0.003447 \\
Sterr. & 0.003857 & 0.000032 & 0.030512 & 0.001586 \\
Median & -0.001299 & 0.000653 & 0.741937 & 0.003226 \\
Stdev. & 0.058235 & 0.000484 & 0.460718 & 0.023947 \\
Variance & 0.003391 & $2.35 \mathrm{E}-07$ & 0.212261 & 0.000573 \\
Kurtosis & 0.688647 & -0.384242 & -1.014469 & 2.756984 \\
Skewness & 0.016203 & -0.425616 & 0.098127 & -0.158592 \\
Range & 0.375825 & 0.001996 & 1.791759 & 0.199153 \\
Min. & -0.209114 & -0.000488 & -0.105361 & -0.095524 \\
Max. & 0.166711 & 0.001508 & 1.686399 & 0.103630 \\
Sum & 0.141125 & 0.136722 & 179.1109 & 0.785828 \\
\hline
\end{tabular}

Note: This table shows the descriptive statistics of the VAR state variables. The sample period 1984:01-2002:12 comprises 228 monthly data points. ER is the excess return on the DSI-2 total stock index with all listed stocks. YS is the term yield spread of the Nikkei Index of Bond Yields. PBR is the average value of the price to book value ratio (in logs) of all stocks trading in the First Section of the Tokyo Stock Exchange. VS is the value yield spread of small stocks, which is the difference between the DSI-2 small-value and small-growth indexes. Sterr. is the standard error and Stdev. is the standard deviation. 
Table 2

Descriptive statistics of the five VAR state variables

\begin{tabular}{|c|c|c|c|c|c|}
\hline & ER & YS & PBR & DEF & BY \\
\hline Mean & 0.000619 & 0.000600 & 0.785574 & 0.026984 & 0.001788 \\
\hline Sterr. & 0.003857 & 0.000032 & 0.030512 & 0.016161 & 0.000102 \\
\hline Median & -0.001299 & 0.000653 & 0.741937 & -0.007281 & 0.001629 \\
\hline Stdev. & 0.058235 & 0.000484 & 0.460718 & 0.244022 & 0.001535 \\
\hline Variance & 0.003391 & $2.35 \mathrm{E}-07$ & 0.212261 & 0.059547 & 0.000002 \\
\hline Kurtosis & 0.688647 & -0.384242 & -1.014469 & 0.906710 & -0.527424 \\
\hline Skewness & 0.016203 & -0.425616 & 0.098127 & 0.873182 & -0.122364 \\
\hline Range & 0.375825 & 0.001996 & 1.791759 & 1.221223 & 0.006956 \\
\hline Min. & -0.209114 & -0.000488 & -0.105361 & -0.407945 & -0.001908 \\
\hline Max. & 0.166711 & 0.001508 & 1.686399 & 0.813278 & 0.005048 \\
\hline Sum & 0.141125 & 0.136722 & 179.1109 & 6.152348 & 0.407580 \\
\hline
\end{tabular}

Note: This table shows the descriptive statistics of the VAR state variables. The sample period 1984:01-2002:12 comprises 228 monthly data points. ER is the excess return on the DSI-2 total stock index with all listed stocks. YS is the term yield spread of the Nikkei Index of Bond Yields. PBR is the average value of the price to book value ratio (in logs) of all stocks trading in the First Section of the Tokyo Stock Exchange. DEF is the growth rate of business failures calculated as the year-on-year rate. BY is the bond yield trading with repurchase agreement at month-end, with a term to maturity of three months, transformed into real terms and a three-month moving average. Sterr. is the standard error and Stdev. is the standard deviation. 
Table 3

VAR parameter estimates using four variables

\begin{tabular}{lllll}
\hline & \multicolumn{1}{c}{ ER } & \multicolumn{1}{c}{ YS } & \multicolumn{1}{c}{ PBR } & \multicolumn{1}{c}{ VS } \\
\hline \hline ER(-1) & 0.034895 & 0.000054 & 0.099180 & 0.009471 \\
& $(0.51071)$ & $(0.41495)$ & $(1.27987)$ & $(0.34700)$ \\
\hline YS(-1) & 9.167112 & $0.974357 * * *$ & 5.844833 & 1.238651 \\
& $(1.07960)$ & $(60.0024)$ & $(0.60691)$ & $(0.36517)$ \\
\hline PBR(-1) & 0.003957 & -0.000008 & $0.997770 * * *$ & 0.001303 \\
& $(0.43922)$ & $(-0.49236)$ & $(97.6439)$ & $(0.36212)$ \\
\hline VS(-1) & -0.140170 & -0.000060 & 0.033829 & $0.250333 * *$ \\
& $(-0.85815)$ & $(-0.19102)$ & $(0.18261)$ & $(3.83651)$ \\
\hline C & -0.007837 & 0.000019 & -0.006800 & 0.000949 \\
& $(-0.73386)$ & $(0.92775)$ & $(-0.56143)$ & $(0.22250)$ \\
\hline \hline Adj. R-squared & $-0.69 \%$ & $94.70 \%$ & $97.94 \%$ & $4.69 \%$ \\
\hline
\end{tabular}

Note: This table provides the OLS parameter estimates for a first-order VAR model including a constant term (C), the risk premium (ER), the term yield spread (YS), the price-book value ratio (PBR), and the value yield spread of small stocks (VS). The sample periods for the dependent variables 1984:02-2002:12 comprise 227 monthly data points. $\cdot(-1)$ is the explanatory variable of the VAR and denotes a lag of one period. Adj. R-squared denotes the adjusted R-squared. The first row for each variable is the estimated coefficients. The values in parentheses are $t$-values.

$* * *$ denotes significance at the $1 \%$ level, $* *$ at the $5 \%$ level, and * at the $10 \%$ level. 
Table 4

VAR parameter estimates using five variables

\begin{tabular}{llllll}
\hline & ER & YS & PBR & DEF & BY \\
\hline \hline ER (-1) & 0.029732 & 0.000063 & 0.084837 & 0.028358 & 0.000542 \\
& {$[0.44259]$} & {$[0.49303]$} & {$[1.11092]$} & {$[0.24599]$} & {$[1.15694]$} \\
\hline YS (-1) & 6.907166 & $0.978928^{* * *}$ & 3.635542 & -17.87396 & $-0.142301^{* *}$ \\
& {$[0.81570]$} & {$[60.6790]$} & {$[0.37768]$} & {$[-1.23002]$} & {$[-2.41014]$} \\
\hline PBR (-1) & -0.018503 & -0.000026 & $0.977109^{* * *}$ & -0.004198 & 0.000018 \\
& {$[-1.49368]$} & {$[-1.09293]$} & {$[69.3886]$} & {$[-0.19747]$} & {$[0.20801]$} \\
\hline DEF $(-1)$ & $-0.036879 * *$ & 0.000050 & $-0.039937 * *$ & $0.911260 * * *$ & -0.000040 \\
& {$[-2.12304]$} & {$[1.51829]$} & {$[-2.02243]$} & {$[30.5691]$} & {$[-0.33078]$} \\
\hline BY (-1) & $7.211536^{* *}$ & $0.012449 *$ & 6.282213 & -3.461354 & $0.945719^{* * *}$ \\
& {$[2.13043]$} & {$[1.93038]$} & {$[1.63257]$} & {$[-0.59586]$} & {$[40.0688]$} \\
\hline C & -0.001084 & 0.000006 & 0.000844 & 0.021503 & $0.000162^{* *}$ \\
& {$[-0.09707]$} & {$[0.28377]$} & {$[0.06652]$} & {$[1.12218]$} & {$[2.07685]$} \\
\hline \hline Adj. R-squared & $1.69 \%$ & $94.86 \%$ & $97.98 \%$ & $83.55 \%$ & $93.09 \%$ \\
\hline
\end{tabular}

Note: The table provides the OLS parameter estimates for the first-order VAR model including a constant term (C), the risk premium (ER), the term yield spread (YS), the price-book value ratio (PBR), the growth rate of business failure (DEF), and the bond yields (BY). The sample periods for the dependent variables 1984:02-2002:12 comprise 227 monthly data points. $\cdot(-1)$ is the explanatory variable of the VAR and denotes a lag of one period. Adj. R-squared denotes the adjusted R-squared. The first row for each variable is the estimated coefficients. The values in parentheses are $t$-values.

$* * *$ denotes significance at the $1 \%$ level, ** at the $5 \%$ level, and * at the $10 \%$ level. 
Table 5

Descriptive statistics for cash flow and discount rate news as generated by the four-variable VAR

\begin{tabular}{lcll}
\hline & DR news & & \multicolumn{2}{c}{ CF news } & \\
\hline \hline Mean & 0.000000 & Mean & 0.000000 \\
Sterr. & 0.003275 & Sterr. & 0.005921 \\
Median & -0.001416 & Median & -0.000947 \\
Stdev. & 0.049342 & Stdev. & 0.089211 \\
Variance & 0.002435 & Variance & 0.007959 \\
Kurtosis & 1.071481 & Kurtosis & 0.908227 \\
Skewness & 0.072473 & Skewness & 0.132476 \\
Range & 0.341018 & Range & 0.591441 \\
Min. & -0.169527 & Min. & -0.296546 \\
Max. & 0.171491 & Max. & 0.294895 \\
Sum & 0.000000 & Sum & 0.000000 \\
\hline
\end{tabular}

Note: This table provides descriptive statistics for the cash flow (CF) and discount rate (DR) news generated from the four-variable VAR with elements RP, YS, PBR, and VS. Sterr. is the standard error and Stdev. is the standard deviation. 
Table 6

Descriptive statistics for cash flow and discount rate news generated by the five-variable VAR

\begin{tabular}{llll}
\hline \multicolumn{2}{c}{ DR news } & & \multicolumn{2}{c}{ CF news } & \\
\hline \hline Mean & 0.000000 & Mean & 0.000000 \\
Sterr. & 0.003332 & Sterr. & 0.002700 \\
Median & 0.000074 & Median & -0.002155 \\
Stdev & 0.050211 & Stdev & 0.040679 \\
Variance & 0.002521 & Variance & 0.001654 \\
Kurtosis & 0.945681 & Kurtosis & -0.350219 \\
Skewness & 0.022871 & Skewness & 0.107653 \\
Range & 0.333853 & Range & 0.204112 \\
Min. & -0.167265 & Min. & -0.105049 \\
Max. & 0.166588 & Max. & 0.105049 \\
Sum & 0.000000 & Sum & 0.000000 \\
\hline
\end{tabular}

Note: The table provides descriptive statistics for cash flow (CF) and discount rate (DR) news generated from the five-variable VAR with elements RP, YS, PBR, DEF, and BY. Sterr. is the standard error and Stdev. is the standard deviation. 
Table 7

Absolute sum, absolute average, and sum of squares of news

\begin{tabular}{l|l:l|l|l}
\hline & \multicolumn{2}{|c|}{ CF news } & \multicolumn{2}{c}{ DR news } \\
\cline { 2 - 5 } & Four variables & Five variables & Four variables & Five variables \\
\hline \hline Absolute sum & 15.13506 & 7.50625 & 8.31925 & 8.64082 \\
Absolute average & 0.06667 & 0.03307 & 0.03665 & 0.03807 \\
Sum of squares & 1.79864 & 0.374 & 0.55022 & 0.56979 \\
\hline
\end{tabular}

Note: The table provides the absolute sum, absolute average, and sum of squares for news generated by the four and five-variable VARs, respectively. Absolute sum is the sum of the absolute value of news; absolute average is the average of the absolute value of news; sum of squares is the sum of the squared value of news. 
Table 8

Variance decomposition of returns

Four variables

\begin{tabular}{l|llll}
\hline & Var(total news) & $\operatorname{Var}(\mathrm{CFN})$ & $\operatorname{Var}(\mathrm{DRN})$ & $-2 \operatorname{Cov}(\mathrm{CFN} . \mathrm{DRN})$ \\
\hline \hline Real value & 0.0034 & 0.0080 & 0.0024 & -0.0070 \\
Ratio & 1.0000 & 2.3725 & 0.7258 & -2.0890 \\
\hline
\end{tabular}

Five variables

\begin{tabular}{l|llll}
\hline & Var(total news) & $\operatorname{Var}(\mathrm{CFN})$ & $\operatorname{Var}(\mathrm{DRN})$ & $-2 \operatorname{Cov}(\mathrm{CFN} . \mathrm{DRN})$ \\
\hline \hline Real value & 0.0033 & 0.0017 & 0.0025 & -0.0009 \\
Ratio & 1.0000 & 0.5076 & 0.7733 & -0.2797 \\
\hline
\end{tabular}

Note: The table provides the variance decomposition for unexpected stock returns, i.e., total news, using four- and five-VAR state variables, respectively. Each column 'Real value', i.e., 'Var (total news)', 'Var $(\mathrm{CFN})$ ', 'Var (DRN)', and '-2 Cov $(\mathrm{CFN}, \mathrm{DRN})$ ', are given as each terms of equation $\operatorname{Var}\left(\mathrm{r}_{\mathrm{t}+1}-\mathrm{E}_{\mathrm{t}} \mathrm{r}_{\mathrm{t}+1}\right)=$ $\operatorname{Var}\left(\mathrm{N}_{\mathrm{CF}, t+1}\right)+\operatorname{Var}\left(\mathrm{N}_{\mathrm{DR}, \mathrm{t}+1}\right)-2 \mathrm{Cov}\left(\mathrm{N}_{\mathrm{CF}, \mathrm{t}+1}, \mathrm{~N}_{\mathrm{DR}, \mathrm{t}+1}\right)$. Dividing 'Real value' by the variance of total news gives 'Ratio' (by definition sums to one). 
Table 9

Beta of each index

\begin{tabular}{|c|c|c|c|c|}
\hline Indices & Portfolio classification & $\mathrm{CF} \beta$ & DR $\beta$ & Total $\beta$ \\
\hline \multirow[t]{33}{*}{33 sectors } & Fishery, Agriculture \& Forestry & 0.210 & 0.617 & 0.827 \\
\hline & Mining & 0.290 & 0.698 & 0.988 \\
\hline & Construction & 0.063 & 0.043 & 0.106 \\
\hline & Foods & -0.085 & -0.178 & -0.262 \\
\hline & Textiles & 0.176 & 0.591 & 0.767 \\
\hline & Pulp \& Paper & 0.316 & 0.669 & 0.985 \\
\hline & Chemicals & 0.101 & 0.065 & 0.166 \\
\hline & Pharmaceutical & -0.142 & -0.173 & -0.316 \\
\hline & Oil \& Coal Products & 0.140 & 0.606 & 0.746 \\
\hline & Rubber Products & 0.325 & 0.858 & 1.183 \\
\hline & Glass \& Ceramic Products & 0.169 & 0.048 & 0.217 \\
\hline & Iron \& Steel & 0.116 & -0.275 & -0.159 \\
\hline & Nonferrous Metals & 0.107 & 0.770 & 0.877 \\
\hline & Metal Products & 0.055 & 0.877 & 0.932 \\
\hline & Machinery & 0.123 & -0.025 & 0.098 \\
\hline & Electric Appliances & 0.177 & -0.170 & 0.007 \\
\hline & Transportation Equipment & 0.125 & 0.559 & 0.683 \\
\hline & Precision Instruments & -0.003 & 0.834 & 0.831 \\
\hline & Other Products & 0.083 & 0.045 & 0.128 \\
\hline & Electric Power \& Gas & 0.341 & -0.483 & -0.141 \\
\hline & Land Transportation & 0.200 & 0.470 & 0.670 \\
\hline & Marine Transportation & -0.026 & 1.240 & 1.214 \\
\hline & Air Transportation & 0.052 & 0.065 & 0.116 \\
\hline & Warehousing \& Harbor & 0.259 & -0.582 & -0.323 \\
\hline & Information \& Communication & 0.322 & 0.761 & 1.082 \\
\hline & Wholesale Trade & 0.107 & 1.338 & 1.445 \\
\hline & Retail Trade & -0.093 & -0.194 & -0.287 \\
\hline & Banks & 0.439 & -0.778 & -0.338 \\
\hline & Securities & 0.820 & 1.121 & 1.941 \\
\hline & Insurance & 0.010 & 1.372 & 1.382 \\
\hline & Other Finance & -0.520 & -0.332 & -0.852 \\
\hline & Real Estate & 0.415 & -0.648 & -0.233 \\
\hline & Services & 0.838 & 0.985 & 1.823 \\
\hline
\end{tabular}


Table 9

Beta of each index -continued

\begin{tabular}{l|lrrr}
\hline Indices & Portfolio classification & CF $\beta$ & DR $\beta$ & Total $\beta$ \\
\hline \hline Daiwa 7 sectors & Material & -0.109 & 1.289 & 1.180 \\
& Manufacturing & -0.599 & -0.320 & -0.919 \\
& Miscellaneous Manufacturing & 0.312 & -0.733 & -0.421 \\
& Transportation \& Utility & 0.972 & 0.885 & 1.858 \\
& Services & -0.005 & 1.394 & 1.389 \\
& Miscellaneous Non-Manufacturing & -0.661 & -0.211 & -0.871 \\
& Financial & 0.557 & -0.777 & -0.220 \\
& Large Non-Financials & 0.974 & 0.829 & 1.803 \\
& Large Financials & 0.010 & 1.405 & 1.415 \\
& Non-Financials Total Index & -0.678 & -0.195 & -0.873 \\
\hline Average & & 0.146 & 0.334 & 0.480 \\
\hline Correlation coef. & & - & - & 0.187 \\
\hline \hline
\end{tabular}

Note: The table provides the value of the betas for each index. 'CF $\beta$ ' denotes the cash flow beta and 'DR $\beta$ ' denotes the discount rate beta. 'Total $\beta$ ' denotes the sum of the two betas. 'Correlation coef.' denotes the correlation coefficient of the two betas. 
Table 10

Regression tests for the three asset-pricing models

\begin{tabular}{|c|c|c|c|c|c|c|}
\hline & \multicolumn{2}{|c|}{ Factor Model } & \multicolumn{2}{|c|}{ CV model } & \multicolumn{2}{|c|}{ CAPM } \\
\hline $\mathrm{g}_{0}$ & $-0.00169 * * *$ & NA & $-0.00251^{* * *}$ & NA & $-0.00151 * *$ & NA \\
\hline Std.error & [0.00046] & NA & [0.00051] & NA & [0.00073] & NA \\
\hline Upper & -0.00088 & NA & -0.00155 & NA & -0.00013 & NA \\
\hline Lower & -0.00269 & NA & -0.00356 & NA & -0.00297 & NA \\
\hline$g_{1}$ & $0.01012 * * *$ & $0.00900 * * *$ & $0.00912 * * *$ & $0.00668 * * *$ & $0.00294 * * *$ & $0.00213^{* * *}$ \\
\hline $\begin{array}{l}\text { Std.error } \\
95 \% \text { BS interval }\end{array}$ & [0.00085] & [0.00126] & [0.00090] & [0.00123] & [0.00088] & [0.00076] \\
\hline Upper & 0.01207 & 0.01159 & 0.01108 & 0.00927 & 0.00481 & 0.00372 \\
\hline Lower & 0.00889 & 0.00687 & 0.00748 & 0.00447 & 0.00143 & 0.00074 \\
\hline $\begin{array}{l}\mathrm{g}_{2} \\
\text { Std.error }\end{array}$ & $\begin{array}{l}0.00036 \\
{[0.00044]}\end{array}$ & $\begin{array}{l}-0.00048 \\
{[0.00049]}\end{array}$ & $\begin{array}{l}0.00326 \\
\text { NA }\end{array}$ & $\begin{array}{l}0.00326 \\
\text { NA }\end{array}$ & $\begin{array}{l}0.00294 * * * \\
{[0.00088]}\end{array}$ & $\begin{array}{l}0.00213 * * * \\
{[0.00076]}\end{array}$ \\
\hline $\begin{array}{l}95 \% \text { BS interval } \\
\text { Upper }\end{array}$ & 000126 & 000051 & NA & NA & 000481 & 000372 \\
\hline Lower & -0.00044 & -0.00145 & NA & NA & 0.00143 & 0.00074 \\
\hline Adj. R-squared & $70.82 \%$ & $60.08 \%$ & $52.17 \%$ & $24.55 \%$ & $28.42 \%$ & $21.24 \%$ \\
\hline RRA coef. & NA & NA & 2.80 & 2.05 & NA & NA \\
\hline
\end{tabular}

Note: The table shows estimated risk prices for the factor model with two betas, the CV model, and the CAPM. $\mathrm{g}_{0}, \mathrm{~g}_{1}$, and $\mathrm{g}_{2}$ are regression estimates of the constant term, the risk price of the cash flow beta, and the risk price of the discount rate beta, respectively. All regressions include White Heteroskedasticity Consistent Covariances. The factor model is regressed with no restriction, the CV model with $\mathrm{g}_{2}=0.00329$, and the CAPM with $g_{1}=g_{2}$. The table reports two regressions for each model, with and without a constant. 'Std. error' denotes the standard error of estimated coefficient. '95\% BS interval' denotes the $95 \%$ confidence interval with bootstrap from 2,500 simulated realizations. 'Upper' is the upper critical value and 'Lower' is the lower critical value. 'Adj, R-squared' is the adjusted R-squared of the regression. 'RRA coef.' is the relative risk aversion coefficient calculated as $\gamma=\mathrm{g}_{1} / \mathrm{g}_{2}$. NA - not applicable.

*** denotes significance at the $1 \%$ level, $* *$ at the $5 \%$ level, and * at the $10 \%$ level. 
Table 11

Regression tests with individual betas

\begin{tabular}{|c|c|c|c|c|}
\hline & \multicolumn{2}{|c|}{ Cash flow beta } & \multicolumn{2}{|c|}{ Discount rate beta } \\
\hline $\mathrm{g}_{0}$ & -0.00159 *** & NA & -0.00056 & NA \\
\hline Std.error & [0.00042] & NA & {$[0.00076]$} & NA \\
\hline $95 \%$ BS interval & & & & \\
\hline Upper & -0.00084 & NA & 0.00010 & NA \\
\hline Lower & -0.00247 & NA & -0.00193 & NA \\
\hline $\mathrm{g}_{1}$ & $0.01024 * * *$ & $0.00870 * * *$ & NA & NA \\
\hline Std.error & [0.00089] & [0.00110] & NA & NA \\
\hline $95 \%$ BS interval & & & & \\
\hline Upper & 0.01238 & 0.01127 & NA & NA \\
\hline Lower & 0.00901 & 0.00689 & NA & NA \\
\hline $\mathrm{g}_{2}$ & NA & NA & 0.00139 & 0.00105 \\
\hline Std.error & NA & NA & [0.00096] & [0.00082] \\
\hline $95 \%$ BS interval & & & & \\
\hline Upper & NA & NA & 0.00295 & 0.00242 \\
\hline Lower & NA & NA & -0.00075 & -0.00077 \\
\hline Adj. R-squared & $71.24 \%$ & $60.43 \%$ & $2.14 \%$ & $3.16 \%$ \\
\hline
\end{tabular}

Note: The table shows estimated risk prices for the single factor model with each beta. $\mathrm{g}_{0}, \mathrm{~g}_{1}$, and $\mathrm{g}_{2}$ are regression estimates of the constant term, the risk price of the cash flow beta, and the risk price of the discount rate beta, respectively. All regressions include White Heteroskedasticity Consistent Covariances. Cash flow beta is the single-factor model with only the cash flow beta, and discount rate beta only includes the discount rate beta. The table reports two regressions for each model, with and without a constant. 'Std. error' denotes the standard error of estimated coefficient. '95\% BS interval' denotes the 95\% confidence interval with bootstrap from 2,500 simulated realizations. 'Upper' is the upper critical value and 'Lower' is the lower critical value. 'Adj, R-squared' is the adjusted R-squared of the regression. NA - not applicable.

$* * *$ denotes significance at the $1 \%$ level, $* *$ at the $5 \%$ level, and $*$ at the $10 \%$ level. 